\title{
PELATIHAN MEMBUAT DESAIN LOGO VECTOR MENGGUNAKAN ADOBE ILLUSTRATOR DAN ADOBE FLASH DI SMK BINA CIPTA PALEMBANG
}

\author{
Novan Wijaya ${ }^{1}$
}

\begin{abstract}
Abstrak: Teknologi informasi secara terus menerus berkembang pesat khususnya di bidang desain grafis yang juga bermanfaat untuk kemajuan dunia pendidikan. Pada ilmu desain grafis dapat memberikan peserta keterampilan dalam berkomunikasi secara visual, bisa melalui teks ataupun gambar untuk menyampaikan sebuah informasi atau pesan dengan menguasi software desain grafis. Keterampilan desain grafis sangat dibutuhkan dalam berbagai bidang usaha, seperti percetakan, advertising, multimedia, fashion, industry dan pendidikan sampai ke industriindustri kreatif lainnya. Software yang digunakan dalam pengabdian masyarakat yaitu Adobe Illustrator. Software yang digunakan dalam pelatihan ini berbasis vektor. Sehingga hasil akhir yang didapatkan berkualitas lebih baik apabila dilakukan pembesaran/zoom. Sehingga target keluaran kegiatan ini adalah peserta dapat mengimplementasikan desain grafis baik di dalam lingkungan sekolah berupa pembuatan majalah dinding atau pengumuman lainnya serta bisa diimplementasikan di dunia pekerjaan yang berhubungan dengan desain grafis.
\end{abstract}

Kata Kunci: Adobe llustrator, Desain Grafis, Vektor.

\section{Training Vector Logo Design Using Adobe Illustrator and Adobe Flash at SMK Bina Cipta Palembang}

\begin{abstract}
Information technology is growing rapidly, especially graphic design which beneficial to the advancement of education. In the science of graphic design can give participants skill to communication visually, either text or images to convey a message. Graphic design skilla are needed in various fields of business such as printing, advertising, multimedia, fashion, industry and education until creative industries. Software used is Adobe Illustrator. Adobe illustrator based on vectors. Final result obtained better than quality if magnification/zoom. Output of this activity is praticipants can implement graphic design either form of making school environment a bulletin board or other announcements can be implemented in the world as well as work related to graphic design.
\end{abstract}

Keywords: Adobe Illustrator, Graphic Design, Vector.

\section{PENDAHULUAN}

Adobe Illustrator adalah salah satu software pengolah gambar yang berbasis vektor. Menurut Tjiharjadi, \& Sanwill (2006), gambar vektor merupakan gambar yang terbentuk bukan dari kumpulan titik melainkan terbentuk dari sejumlah garis dan kurva. Karena gambar jenis vektor ini bukan terdiri dari titik, maka apabila tampilan gambar ini diperbesar tetap tidak akan kehilangan detailnya sehingga kualitas gambarnya tetap baik. Contoh gambar ini adalah teks dan logo. Perangkat lunak yang sering digunakan untuk mengolah gambar jenis vektor ini adalah Adobe Illustrator, CorelDRAW, Freehand, Inkscape, dan lain-lain. Monitor biasanya akan menampilkan gambar dalam bentuk piksel, maka semua gambar baik jenis vector maupun

\footnotetext{
${ }^{1}$ Program Studi Manajemen Informatika, STMIK GI MDP; email: novan.wijaya@mdp.ac.id.
} 
bitmap akan ditampilkan dalam bentuk piksel. Gambar ini mengandung unsur matematis seperti arah, ukuran sudut, ketebalan, warna, dan lain sebagainya.

Kurniawan (2011) menyebut bahwa tampilan bitmap sering disebut dengan gambar raster yaitu tampilan gambar yang terdiri dari titik-titik atau piksel. Masing-masing piksel ini mempunyai lokasi serta warna tersendiri yang secara keseluruhan membentuk sebuah tampilan gambar pada saat gambar diperbesar. Kehalusan tampilan gambar ini sangat tergantung kepada resolusi serta titik atau piksel yang membentuk gambar tersebut. Apabila gambar ini diperbesar maka ini kelihatan kotak-kotak, semakin besar tampilan gambar maka semakin besar pula kotak-kotak tersebut, yang sebetulnya merupakan tampilan piksel yang diperbesar. Contoh gambar bitmap antara lain photo, gambar-gambar hasil scanner serta gambar yang dihasilkan dari software grafis seperti Adobe Photoshop, Corel PHOTO-PAINT, GIMP.

Adobe Flash adalah Software pembuat vektor animasi 2 Dimensi, dulunya bernama Macromedia Flash, hingga pada akhirnya Adobe mengakuisisi / membeli semua produk Macromedia, sehingga namanya menjadi Adobe Flash. Software ini mempunyai file extention (.swf) dan dapat digunakan pada website yang sudah dipasang Adobe Flash Player. Flash dirancang oleh Adobe sebagai pembuat animasi 2 Dimensi yang mudah dan ringan, sehingga banyak digunakan untuk memberikan efek animasi pada website, CD interaktif atau semacamnya. Pada software ini hanya sebagai pendukung dalam pembuatan desain logo vector. Dikarenakan pada adobe flash kita hanya membutuhkan beberapa tool untuk menutupi kekurangan tool yang ada di adobe illustrator.

Berdasarkan keunggulan dan kegunaan kedua aplikasi desain grafis di atas, maka penting untuk diadakan program pelatihan. Sehingga, adanya pelatihan ini, peserta dapat, 1) pengalaman membuat logo vector secara praktik dan interaktif; 2) menggunakan imajinasi kreativitas untuk menerapkan warna pada logo vector sehingga menjadi lebih menarik; dan 3) Implementasi teknologi secara langsung.

\section{METODE PELAKSANAAN}

Teknis penyampaian materi pelatihan menggunakan metode presentasi (ceramah) dan praktik secara langsung. Sementara bimbingan interaktif pada saat peserta mengalami kesulitan atau memberikan pertanyaan dalam menyelesaikan materi logo vector secara teknis dibantu oleh rekan yang lainnya. Peserta menggunakan PC yang telah disediakan oleh SMK Bina Cipta Palembang. Pada saat satu anggota tim memberikan penjelasan, maka anggota lainnya mendampingi peserta untuk memberikan bimbingan atas kendala yang dihadapi selama pelatihan. Harapan tim pelaksana, agar pelatihan ini dapat menjadi motivasi dan mendorong semangat untuk mengoptimalkan kemampuannya bagi peserta di SMK Bina Cipta Palembang, selain itu memberikan nilai tambah bagi pihak sekolah. 


\section{HASIL DAN PEMBAHASAN}

Kegiatan pengabdian ini dilaksanakan pada hari kamis tanggal 12 Mei 2016 bertempat bengkel lab komputer SMK Bina Cipta Palembang yang dihadiri oleh kelas $\mathrm{X}$ jurusan TKJ yang berjumlah 36 orang terdiri dari guru dan siswa, dimulai pada pukul 10.00 WIB sampai dengan pukul 13.00 WIB yang dibagi menjadi 2 sesi. Materi disampaikan menjadi dua sesi dikarenakan keterbatasan sarana komputer yang tersedia. Masing-masing materi disampaikan lebih kurang 100 menit. Materi pertama yang disampaikan mengenai penggunaan aplikasi Adobe Illustrator dalam membuat logo vector, selanjutnya disampaikan materi menggunakan aplikasi Adobe Flash, seperti tampak pada Tabel 1.

Kegiatan pengabdian masyarakat yang diimplementasikan oleh STMIK GI MDP Program Studi Manajemen Informatika direspon sangat baik oleh pihak SMK Bina Cipta Palembang. SMK Bina Cipta Palembang, khususnya jurusan Teknik Komputer Jaringan (TKJ), dimana kurikulum yang digunakan masih fokus ke bagian jaringan komputer. Dengan adanya kegiatan pengabdian kepada masyarakat yang dilakukan di sana, manfaat yang diperoleh adalah: Pertama, seluruh peserta dapat mengimplementasikan atau menghasilkan desain grafis yang menarik. Kedua, peserta juga dapat mengikuti berbagai macam lomba desain grafis yang ada karena software adobe illustrator merupakan software umum yang biasa dipakai untuk mengikuti lomba internasional. Ketiga, peserta meningkatkan kreativitas atau berimajinasi berupa gambar.

Tabel 1. Materi yang disampaikan

\begin{tabular}{|c|c|}
\hline Adobe Illustrator & Adobe Flash \\
\hline $\begin{array}{l}\text { 1. Pengenalan tools pada adobe } \\
\text { illustrator } \\
\text { 2. Pengenalan dan penerapan gradiasi } \\
\text { 3. Pengenalan dan penerapan pen tools } \\
\text { 4. Pengenalan dan penerapan rectangle } \\
\text { tool } \\
\text { 5. Pengenalan dan penerapan shaping } \\
\text { builder tool } \\
\text { 6. Latihan membuat logo vector Flight. } \\
\text { 7. Save dan Export file }\end{array}$ & $\begin{array}{l}\text { 1. Pengenalan tools pada adobe } \\
\text { flash. } \\
\text { 2. Pengenalan Line. } \\
\text { 3. Pemberian warna. } \\
\text { 4. Mengenal fungsi Eyedroper tool. } \\
\text { 5. Konversi file agar dapat di terapkan } \\
\text { di adobe illustrator. }\end{array}$ \\
\hline
\end{tabular}




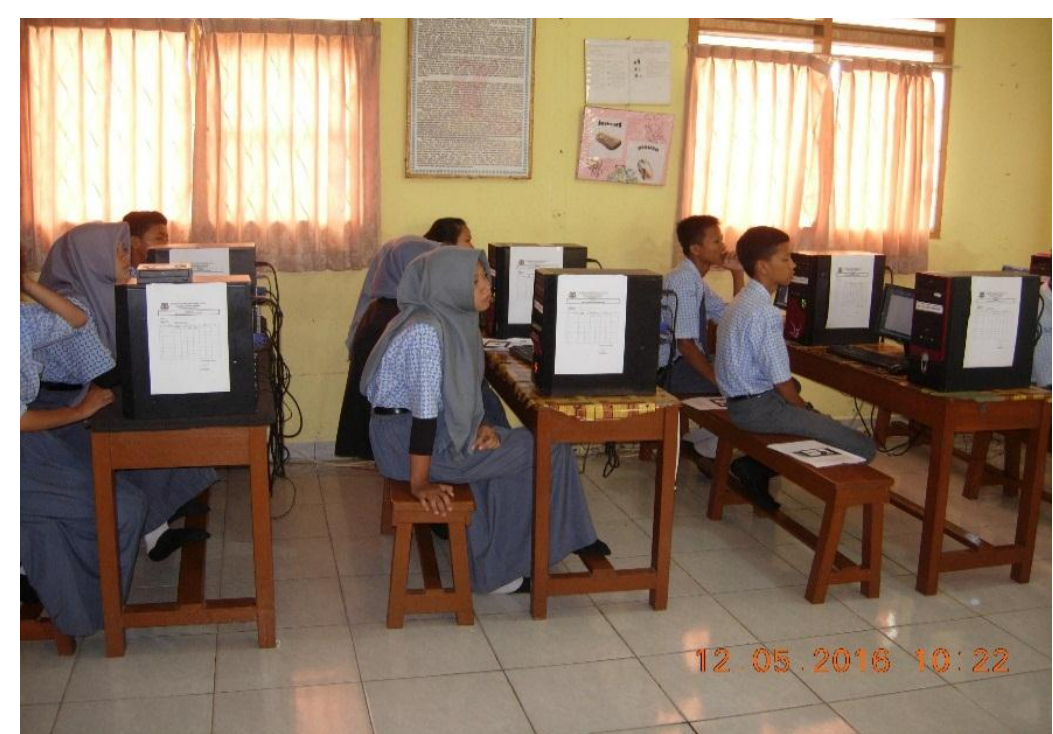

Gambar 1. Peserta memperhatikan penjelasan dari intruktur

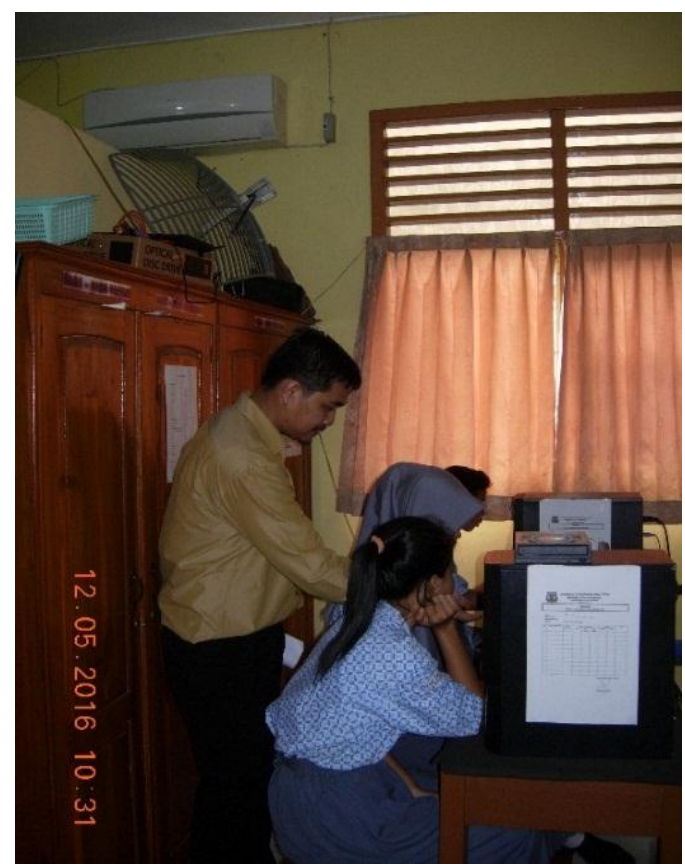

Gambar 2. Instruktur membantu para peserta

\section{KESIMPULAN}

Kegiatan pelatihan merupakan salah satu kegiatan pengabdian kepada masyarakat yang dilakukan di suatu sekolah. Metode presentasi (ceramah) yang digunakan oleh instruktur cukup membantu para peserta sehingga peserta menjadi interaktif dalam melakukan pertanyaan mengenai desain grafis. Para 
peserta sudah bisa mengimplementasikan berbagai logo dengan tingkat kreativitas masing-masing. Persoalan yang terjadi para pesera memerlukan perhatian dan motivasi dari berbagai pihak atau kerjasama antara pihak percetakan, advertising, multimedia dan sebagainya agar peserta mampu mengasah sejauh mana tingkat kreativitasnya dalam bidang desain grafis khususnya menggunakan software adobe illustrator.

\section{REFERENSI}

Tjiharjadi, S., \& Sanwill, S. (2015). Watermarking citra digital menggunakan teknik amplitude modulation. Jurnal Informatika, 2(2), 109-121.

Rahmad, I. F., \& Kurniawan H. (2011). Kompresi file citra bitmap menggunakan algoritma RLE dan LZ78. CSRID Journal, 3(2), 81-92. 